УДК 634.1:631.52

DOI: 10.30679 / 2219-5335-2018-2-50-1-12

СОЗДАНИЕ

НОВЫХ СОРТОВ

И ЭЛИТНЫХ ФОРМ ЯБЛОНИ, ПЕРСПЕКТИВНЫХ ДЛЯ ЮГА РОССИИ

Ульяновская Елена Владимировна

д-р с.-х. наук

зав. лабораторией сортоизучения

и селекции садовых культур

e-mail: ulyanovskaya_e@mail.ru

Шадрина Жанна Александровна канд. экон. наук, доцент

зав. лабораторией экономики

Кочьян Гаянэ Агоповна

канд. экон. наук

научный сотрудник

лаборатории экономики

Федеральное государственное

бюджетное научное учреждение

«Северо-Кавказский федеральный

научный иентр садоводства,

виноградарства, виноделия»,

Краснодар, Россия

Цель данных исследований - создать новые сорта и элитные формы яблони разной плоидности с комплексом ценных агробиологических признаков для формирования эколого-адаптивных систем ведения плодоводства.

Селекционное обновление отечественного сортимента яблони позволит успешно решать проблемы эффективного импортозамещения в отрасли садоводства Северо-Кавказского региона России.

Объекты исследований - генотипы яблони разной плоидности и генетического происхождения. Исследования проводили согласно общепринятым программам и методикам селекции и сортоизучения плодовых культур. В статье дана комплексная оценка основных агробиологических признаков новых
UDC 634.1:631.52

DOI: 10.30679 / 2219-5335-2018-2-50-1-12

\section{CREATION OF NEW \\ APPLE-TREE VARIETIES \\ AND ELITE FORMS \\ PERSPECTIVE \\ FOR THE SOUTH OF RUSSIA}

Ulyanovskaya Elena Vladimirovna

Dr. Sci. Agr.

Head of Laboratory of Variety study

and Breeding of Garden crops

e-mail: ulyanovskaya_e@mail.ru

Shadrina Zhanna Aleksandrovna

Cand. Econ. Sci., Docent

Head of the Economics Laboratory

Kochyan Gayane Aghopovna

Cand. Econ. Sci.

Research Associate

of Laboratory of Economics

Federal State Budget

Scientific Institution

"North Caucasian Federal

Scientific Center of Horticulture,

Viticulture, Wine-making",

Krasnodar, Russia

The purpose of these study is to create the new apple varieties and elite forms of apples of different ploidy with a set of valuable agrobiological features for the formation of ecologically adaptive fruit growing systems. Breeding renovation of the domestic apple assortment will allow to successfully solve the problems of effective import substitution in the gardening industry of the North Caucasus Region of Russia. The objects of research are the apple genotypes of different ploidy and genetic origin. The study were carried out according to the generally accepted programs and methods of breeding and varieties of fruit crops. The article gives a comprehensive assessment of the main agrobiological characteristics 
иммунных к парше сортов яблони и экономической эффективности их возделывания в условиях Краснодарского края. Изучены скороплодность сортов яблони, регулярность плодоношения, урожайность, устойчивость растений к парше, качество и стандартность плодов. В процессе изучения генетического потенциала растений яблони выделены 2 иммунные к парше элитные формы, Созданные в СКФНЦСВВ совместно с ВНИИСПК, превосходящие стандартные сорта по комплексу хозяйственно ценных и адаптивно значимых признаков. Дана краткая характеристика новых иммунных к парше элитных форм яблони Экзотика и Розовый закат, сортов Амулет и Джин. У сортов Амулет и Джин отмечена высокая урожайность (35,0-38,0 т/га).

Рассчитаны показатели экономической Эффективности выращивания новых сортов (прибыль от реализации и рентабельность). Для промышленного возделывания выделены наиболее перспективные сорта яблони - такие как Амулет, Джин. Высокие показатели экономической Эффективности выращивания этих сортов обусловлены наиболее оптимальным Сочетанием у них иммунитета к парше с комплексом важнейших хозяйственных признаков: скороплодность, высокая урожайность и регулярность плодоношения, высокое качество и стандартность плодов.

Ключевые слова: СОРТ, ЯБЛОНЯ, ИММУНИТЕТ, ПАРША, ПРОДУКТИВНОСТЬ, ЭКОНОМИЧЕСКАЯ ЭФФЕКТИВНОСТЬ of new apple varieties immune to scab and the economic efficiency of their cultivation in the Krasnodar Territory. The early ripening of apple cultivars, the regularity of fruiting, the yield capacity, the resistance of plants to scab, the quality and the standard of fruits have been studied. In the process of studying the genetic potential of apple plants, 2 elite immune forms, created in NCFSCHVW jointly with ARRIFCB, are selected, which surpass the standard varieties according to a set of economic valuable and adaptive significant characteristics. A shot description of the new immune to scab apple elite forms of Exotics and the Rozovy Zakat, the varieties of Amulet and Gin is given. The Amulet and Gin varieties have the high yield capacity (35.0-38.0 t/ha). The indicators of economic efficiency of new varieties cultivation (profit from sale and profitability) are calculated. For industrial cultivation, the most promising varieties of apple trees are selected, such as Amulet, Gin. High indexes of economic efficiency of cultivation of these varieties are due to the most optimal combination of their immunity to scab with a complex and of important economic signs: fast fruiting, the high yield capacity and regularity of fruiting, the high quality and standard of fruits.

Key words: VARIETY, APPLE-TREE, IMMUNITY, SCAB, PRODUCTIVITY, ECONOMIC EFFICIENCY

Введение. Оптимизация современного промышленного сортимента яблони Северо-Кавказского региона предполагает создание новых генотипов с улучшенными показателями адаптивности, устойчивости к грибным патогенам, продуктивности и качества плодов, пригодных для закладки экологоадаптивных насаждений интенсивного типа в условиях юга России [1-3]. 
Плодоводство и виноградарство Юга России № 50(02), 2018 г.

Основное направление селекционного совершенствования яблони в России и в мире - совмещение в генотипе высокого уровня устойчивости к абио- и биотическим стрессорам региона и улучшенных показателей качества плодов [1, 4-10]. В селекции сельскохозяйственных растений наиболее распространённый метод, с помощью которого получено большинство современных сортов, - межсортовая гибридизация. Более сложный и трудоёмкий метод селекции - отдалённая гибридизация. Однако, для совмещения в одном генотипе ценных показателей качества плодов и адаптивности в селекции многих сельскохозяйственных растений, в том числе и в селекции плодовых культур, наиболее перспективно и результативно сочетание методов отдаленной (межвидовой) и внутривидовой гибридизации и полиплоидии [8, 11-15].

В настоящее время перспективным направлением исследований является создание отечественных биоресурсов основной плодовой культуры яблони (в частности, южных высококачественных сортов, иммунных и устойчивых к парше) на основе классических и модифицированных методов селекции, в том числе направленных интервалентных скрещиваний с использованием усовершенствованного метода полиплоидии [15].

Селекционное обновление отечественного сортимента яблони позволит успешно решать проблемы эффективного импортозамещения в отрасли садоводства Северо-Кавказского региона России.

Цель исследований - создать новые сорта и элитные формы яблони разной плоидности с комплексом ценных агробиологических признаков для формирования эколого-адаптивных систем ведения плодоводства.

Объекты и методы исследований. Объекты исследований - генотипы яблони разной плоидности и генетического происхождения. Сады 19982014 гг. посадки; подвой М9. Схемы посадки 5х2; 5x1,5; 4x1 м. В работе использованы селекционные программы и методики: «Программа СевероКавказского центра по селекции плодовых, ягодных, цветочно- 
Плодоводство и виноградарство Юга России № 50(02), 2018 г.

декоративных культур и винограда на период до 2030 года» [16]; «Современные методологические аспекты организации селекционного процесса в садоводстве и виноградарстве» [1]; «Программа и методика сортоизучения плодовых, ягодных и орехоплодных культур» [17]; «Программа и методика селекции плодовых, ягодных и орехоплодных культур» [18] и др. [19, 20]. В селекции яблони применен усовершенствованный в СКФНЦСВВ метод полиплоидии, основанный на дополнительной модификации методики возвратных скрещиваний в селекции на иммунитет к парше путем использования в качестве реккурентного родителя при каждом последующем беккроссе полиплоидного сорта или формы [15].

Для ускорения селекционного процесса использован комплекс методов: жесткий отбор по морфологическим признакам сеянцев в селекционной школке, отбор на искусственном инфекционном фоне на иммунитет (ген Vf) к парше (совместно с ВНИИСПК), прививка на скороплодный подвой, совмещение во времени и пространстве первичного и конкурсного, конкурсного и государственного сортоиспытания.

Обсужнение результатов. Один из основных недостатков современного сортимента яблони юга России - достаточно низкая устойчивость многих сортов, особенно интродуцированных, к действию комплекса абиотических и биотических стрессоров региона [1]. Поэтому перспективное изменение южного сортимента яблони за счет пополнения новыми генотипами с олиго- и полигенным типом устойчивости к основным грибным патогенам и, в частности к парше, способствует распространению современных природоохранных и ресурсосберегающих технологий производства плодов яблони [15].

В 2017 году в процессе изучения генетического потенциала селекционных форм яблони выделены 2 иммунные к парше элитные формы - Экзотика и Розовый закат (созданные в СКФНЦСВВ совместно с ВНИИСПК), обладающие комплексом ценных агробиологических признаков (рис. 1). 


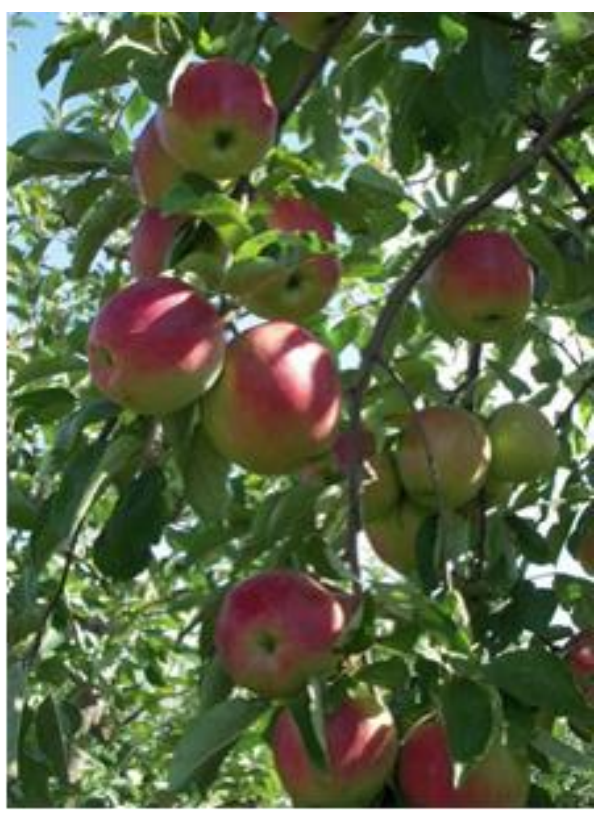

Элитная форма Экзотика

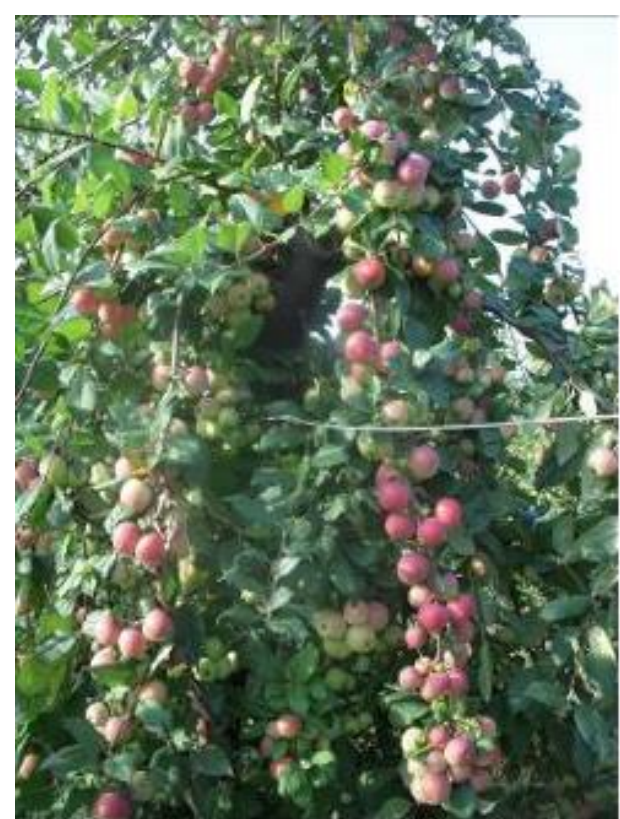

Элитная форма Розовый закат

Рис. 1. Элитные формы яблони селекции СКФНЦСВВ совместно с ВНИИСПК

Розовый закат (Мелба х M. floribunda х Ренет Симиренко) - элитная форма осеннего срока созревания. Дерево слаборослое, крона плакучая. Скороплодность высокая. Плодоношение обильное, регулярное. Морозо- и засухоустойчива, имеет иммунитет к парше. Плоды округлой формы, около 2,4-2,6 см в диаметре, с ярким розовым румянцем, хорошего вкуса, пригодны для потребления в свежем виде и переработки. Перспективна для приусадебного садоводства, в том числе в качестве фокусного растения при использовании в декоративных целях.

Экзотика (Айдаред х Балсгард 0247Е) - триплоидная элитная форма зимнего срока созревания. Дерево средней силы роста. Имеет ген иммунитета к парше (Vf), засухо- и морозоустойчива. Скороплодна, урожайность высокая - до 34 т/га. Плоды крупные (средняя масса 293 г), одномерные, округлые, с ярким малиновым румянцем по большей части плода. Мякоть кремоватая, плотная, сочная, мелкозернистая, отличного десертного вкуса, слегка напоминающего вкус манго (дегустационная оценка вкуса 4,8 балла), с нежным ароматом. В связи с низкой жизнеспособностью пыльцы, является плохим опылителем. 
Плодоводство и виноградарство Юга России № 50(02), 2018 г.

Таким образом, активное использование в селекционном процессе метода отдаленной гибридизации и усовершенствованного метода полиплоидии позволяет создавать перспективные для селекции и производства генотипы яблони, сочетающие иммунитет к парше с комплексом хозяйственно-ценных признаков.

Основной элемент адаптивной технологии возделывания яблони, в отличие от традиционной, - современный сортимент, включающий районированные и перспективные сорта, сочетающие иммунитет или высокую устойчивость к парше с комплексом ценных биологических и производственных признаков.

На основании многолетних исследований в СКФНЦСВВ созданы перспективные для адаптивной технологии возделывания иммунные и устойчивые к парше сорта яблони нового поколения различных сроков созревания - от раннелетнего (3-я декада июня) до зимнего. Большинство из этих сортов получены в результате комплексной научноисследовательской работы в СКФНЦСВВ совместно с ВНИИСПК, согласно договору о творческом содружестве по двум программам исследований «Иммунитет» (с 1985 г.) и «Полиплоид» (с 1983 г.).

В рамках решения проблемы эффективного импортозамещения особенно перспективны для южного региона России высококачественные, иммунные и устойчивые к парше сорта яблони отечественной, в том числе региональной селекции. На основе многолетнего изучения адаптационного потенциала иммунных и устойчивых к парше сортов яблони коллекции СКФНЦСВВ для производственного испытания в различных природных зонах Северо-Кавказского региона выделены новые сорта - Амулет и Джин.

Амулет (Редфри х Папировка тетраплоидная) - иммунный к парше сорт позднелетнего срока созревания. Получен в СКФНЦСВВ совместно с ВНИИСПК (рис. 2). 


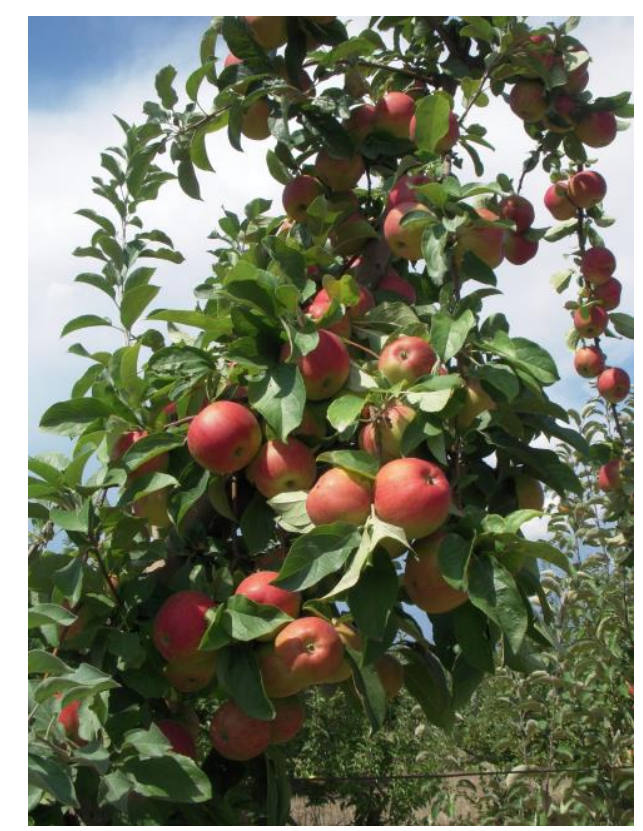

Рис. 2. Иммунный к парше сорт яблони Амулет

Сорт слаборослый, с высокой скороплодностью, в плодоношение на подвое М9 вступает на 1-2-й год после посадки. Имеет обильное плодоношение (до 30-35 т/га). Сочетает комплекс ценных адаптивных признаков иммунитет к парше (имеет ген Vf), устойчивость к мучнистой росе, засухоустойчивость и морозоустойчивость в условиях региона.

Плоды выше среднего и среднего размера, с ярко-малиновым размытым румянцем практически по всему плоду. Мякоть кремовая, очень сочная, хорошего кисло-сладкого вкуса (4,7 балла), с нежным ароматом. Используется в свежем виде. Перспективен для приусадебного использования, особенно на небольшом участке, так как сочетает слаборослость, скороплодность, компактность кроны, иммунитет к парше, высокую урожайность, имеет яркие нарядные плоды среднего размера, очень хорошего вкуса.

Джин (Айдаред х Балсгард 0247Е) - иммунный к парше сорт позднеосеннего срока созревания. Получен в СКФНЦСВВ совместно с ВНИИСПК (рис. 3). Дерево сдержанного роста, крона компактная, удобная для уборки. Тип плодоношения смешанный. Вступает в плодоношение на 2-й год после посадки (на М9, СК2), быстро наращивает урожайность в 
молодом возрасте. Триплоид. Является плохим опылителем для других сортов. Имеет ген иммунитета к парше Vf, высокую полевую устойчивость к мучнистой росе.

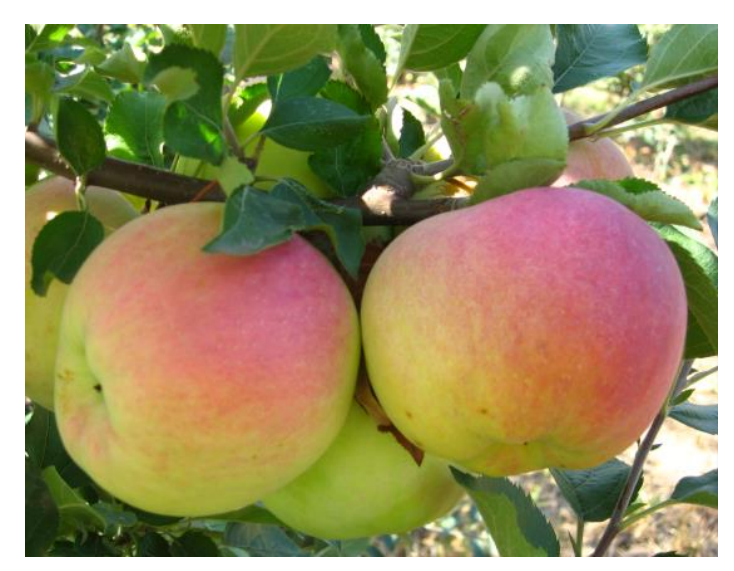

Рис. 3. Иммунный к парше сорт яблони Джин

Сорт засухо- и морозоустойчив. Урожай - до 38 т/га. Плоды крупные (265 г), одномерные, округлые, с красным румянцем, сочные, десертного вкуса (4,7 балла) с нежным ароматом. Достоинства сорта: иммунитет к парше, крупноплодность, десертный вкус плодов, равномерная нагрузка дерева плодами.

Оценка экономической эффективности выращивания иммунных к парше сортов яблони Амулет и Джин выполнена совместно с лабораторией экономики СКФНЦСВВ (рук. Шадрина Ж.А.) (табл. 1, 2).

Таблица 1 - Основные агробиологические признаки новых иммунных к парше сортов яблони (подвой М9, схема 5х2), ОПХ «Центральное»

\begin{tabular}{|c|c|c|c|c|}
\hline Сорт & $\begin{array}{c}\text { Урожайность, } \\
\text { т/га }\end{array}$ & $\begin{array}{c}\text { Стандартность, } \\
\%\end{array}$ & $\begin{array}{c}\text { Год вступления } \\
\text { в плодоношение }\end{array}$ & $\begin{array}{c}\text { Устойчивость } \\
\text { к парше }\end{array}$ \\
\hline \multicolumn{5}{|c|}{ Летний срок созревания } \\
\hline Редфри (к) & 28,0 & 75 & 2 & иммунитет \\
\hline Амулет & 35,0 & 85 & $1-2$ & иммунитет \\
\hline \multicolumn{7}{|c|}{ Осенний срок созревания } \\
\hline Прима (к) & 30,5 & $75-80$ & $2-3$ & иммунитет \\
\hline Джин & 38,0 & $85-90$ & 2 & иммунитет \\
\hline
\end{tabular}

Более высокая экономическая эффективность отмечена у иммунных к парше сортов Амулет и Джин (прибыль с 1 га - 313,3 тыс. руб. и 428,3 тыс. 
руб. соответственно). По уровню рентабельности новый сорт яблони Амулет на 24,1 п.п. превосходит контрольный сорт Редфри (в группе летних сортов), а сорт Джин на 25,6 п.П. превосходит контрольный сорт Прима (в группе осенних сортов). Это обусловлено более высокими показателями по комплексу ценных хозяйственных признаков (скороплодность, урожайность, регулярность плодоношения, стандартность плодов) у новых сортов.

Таблица 2 - Экономическая эффективность производства плодов сортов яблони в условиях ОПХ «Центральное»

\begin{tabular}{|c|c|c|c|c|c|c|}
\hline Сорт & $\begin{array}{l}0 \\
0 \\
0 \\
0 \\
0 \\
0 \\
0 \\
0 \\
0 \\
0 \\
0 \\
0 \\
0\end{array}$ & 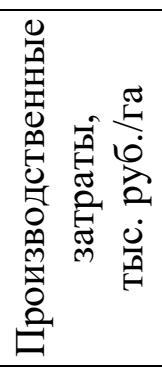 & 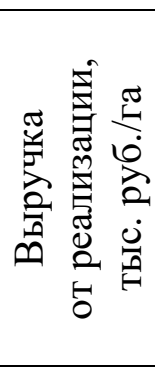 & 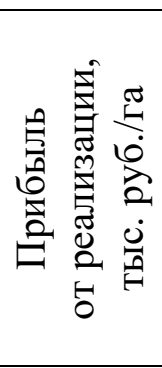 & 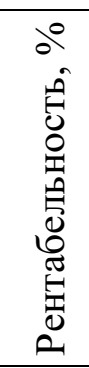 & 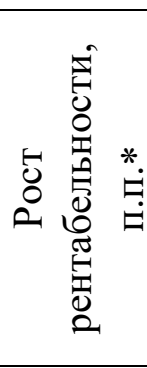 \\
\hline \multicolumn{7}{|c|}{ Летний срок созревания } \\
\hline Редфри (к) & 2300 & 644,0 & 763,0 & 119,0 & 18,5 & - \\
\hline Амулет & 2100 & 735,0 & 1048,3 & 313,3 & 42,6 & 24,1 \\
\hline \multicolumn{7}{|c|}{ Осенний срок созревания } \\
\hline Прима (к) & 2216 & 675,9 & 876,9 & 201,0 & 29,7 & - \\
\hline Джин & 2038 & 774,4 & 1202,7 & 428,3 & 55,3 & 25,6 \\
\hline
\end{tabular}

* п.п.- процентные пункты

В 2017 году получен патент на новый сорт яблони Ника. В условиях Краснодарского края (ОПХ «Центральное») иммунный к парше сорта Ника показал более высокую экономическую эффективность в сравнении с контрольным сортом Айдаред (прибыль с 1 га у сорта Ника - 534,3 тыс. руб., у сорта Айдаред - 257,4 тыс. руб.). Таким образом, по уровню рентабельности новый сорт Ника на 40,0 п.п. превосходит широко распространенный сорт Айдаред (контроль), что обусловлено сочетанием у нового сорта более высоких показателей по комплексу агробиологических признаков (скороплодность, урожайность, регулярность плодоношения, стандартность плодов, иммунитет к парше).

Иммунный к парше сорт яблони Ника передан для экологического и производственного испытания в ООО «Интеринвест» и ООО «Новозаведенное» Ставропольского края, в СПК «Де-Густо» РСО-Алания. 
Плодоводство и виноградарство Юга России № 50(02), 2018 г.

Bblводы. Для производственного испытания в различных природных зонах Северо-Кавказского региона рекомендованы новые, выделенные в результате проведенных научных исследований, высококачественные, иммунные к парше сорта яблони, с комплексом хозяйственно-ценных и адаптивно-значимых признаков и свойств - позднелетний Амулет, позднеосенний Джин, зимний Ника, в сравнении с контрольными районированными сортами имеющие более высокую экономическую эффективность.

Селекция новых иммунных к парше сортов яблони на основе классических и современных методов создания и оценки гибридного материала и дальнейшее их использование для оптимизации промышленного сортимента перспективных генотипов региональной селекции позволит:

- повысить экономическую эффективность отрасли садоводства юга России и ускорить решение проблемы импортозамещения в отрасли;

- получить высококачественную продукцию отечественного производства на основе сортов яблони региональной селекции;

- улучшить экологическую обстановку в регионе за счет снижения количества обработок средствами химической защиты плодовых насаждений.

\section{Литература}

1. Современные методологические аспекты организации селекционного процесса в садоводстве и виноградарстве. - Краснодар: СКЗНИИСиВ, 2012. - 569 с.

2. Пшеноков, А.Х. Комплексная оценка исходного материала яблони для селекции сортов нового поколения / А.Х. Пшеноков, А.С. Шидакова, Р.Ш. Заремук, И.И. Супрун // Политематический сетевой электронный научный журнал Кубанского государственного аграрного университета. - 2013. - № 93. - С. 889-898.

3. Заремук, Р.Ш. Подбор перспективных сортов для оптимизации яблони в условиях Чеченской республики / Р.Ш. Заремук, Х.Э. Мамалова // Политематический сетевой электронный научный журнал Кубанского государственного аграрного университета. - 2014. - № 97. - С. 718-732.

4. Fischer C. Testing scab-resistance stability of new resistant cultivars within the apple breeding program // Fischer C., Schreiber H., Buttner R., Fischer M. / Acta Horticulturae. - 1999. - V. 484. - P. 449-454.

5. Janick J. History of the PRI apple breeding program / Acta Horticulturae. - 2002. V. 595. - P. 55-60. 
6. Durel C.E. Genetic dissection of partial resistance to rase 6 of Venturia inaequalis in apple // Durel C.E., Parisi L., Laurens F., Van de Weg W.E., Leirbherd R., Jourjon V.F. / Genome. - 2003. - V. 46(2). - P. 224-234.

7. Afunian M.R. Linkage Vfa4 in Malus $x$ domestica and Malus floribunda with Vf resistanse to the apple scab pathogen Venturia inaequalis / Afunian M.R., Goodwin P.H., Hunter D.M. // Plant Pathology. - 2004. - V. 53. - P. 461-467.

8. Седов, Е.Н. Селекция и новые сорта яблони / Е.Н. Седов. - Орел: ВНИИСПК, 2011. $-624 \mathrm{c}$.

9. Якуба, Г.В. Структура патогенного комплекса возбудителей микозов наземной части растения яблони в условиях изменения климата / Г.В. Якуба // Научные труды ГНУ СКЗНИИСиВ - Том 5. - Краснодар: ГНУ СКЗНИИСиВ. - 2014. - С. 151-157.

10. Савельева, Н.Н. Биологические и генетические особенности яблони и селекция иммунных к парше и колонновидных сортов / Н.Н. Савельева. - Мичуринскнаукоград РФ, 2016. - 280 с.

11. Седов, Е.Н. Селекция яблони на полиплоидном уровне / Е.Н. Седов, Г.А. Седышева, 3.М. Серова, - Орел: ВНИИСПК, 2008. - 367 с.

12. Седов, Е.Н. Создание новых полиплоидных сортов яблони с генетической устойчивостью к парше / Е.Н. Седов, Г.А. Седышева, 3.М. Серова, Е.В. Ульяновская // Садоводство и виноградарство, 2009. - №1. - С.14-15.

13. Еремин, Г.В. Полиплоидия / Г.В. Еремин, Е.В. Ульяновская, В.В. Ковалева // Современные методологические аспекты организации селекционного процесса в садоводстве и виноградарстве. - Краснодар: СКЗНИИСиВ, 2012. - С. 113-127.

14. Sedov, E. Creation of triploid grades opens a new era in apple-tree selection / E. Sedov, G. Sedysheva, Z. Serova, E. Ulyanovskaya. // Russian Journal of Horticulture. 2014. - T.1. - № 1. - C. 17-24.

15. Ульяновская, Е.В. Ускоренное создание иммунных к парше сортов яблони с использованием молекулярно-генетических методов исследования / Е.В. Ульяновская, И.И. Супрун, Е.Н. Седов, Г.А. Седышева, 3.М. Серова. - Краснодар, 2011. - 55 с.

16. Программа Северо-Кавказского центра по селекции плодовых, ягодных, цветочно-декоративных культур и винограда на период до 2030 года. - Краснодар: СКЗНИИСиВ, 2013. - 202 с.

17. Программа и методика сортоизучения плодовых, ягодных и орехоплодных культур. - Орел, 1999. - 606 с.

18. Программа и методика селекции плодовых, ягодных и орехоплодных культур. - Орел, 1995. - 503 с.

19. Комплексная программа по селекции семечковых культур в России на 20012020 гг. - Орел, 2001. - 29 с.

20. Методика проведения испытаний на отличимость, однородность и стабильность. Яблоня. RTG/0014/2 // http://www.gossort.com/mtd_dus.html [Электронный peсурс]. -2010 .

\section{References}

1. Sovremennye metodologicheskie aspekty organizacii selekcionnogo processa v sadovodstve i vinogradarstve. - Krasnodar: SKZNIISiV, 2012. - 569 s.

2. Pshenokov, A.H. Kompleksnaja ocenka ishodnogo materiala jabloni dlja selekcii sortov novogo pokolenija / A.H. Pshenokov, A.S. Shidakova, R.Sh. Zaremuk, I.I. Suprun // Politematicheskij setevoj jelektronnyj nauchnyj zhurnal Kubanskogo gosudarstvennogo agrarnogo universiteta. - 2013. - № 93. - S. 889-898. 
3. Zaremuk, R.Sh. Podbor perspektivnyh sortov dlja optimizacii jabloni v uslovijah Chechenskoj respubliki / R.Sh. Zaremuk, H.Je. Mamalova // Politematicheskij setevoj jelektronnyj nauchnyj zhurnal Kubanskogo gosudarstvennogo agrarnogo universiteta. - 2014. № 97. - S. 718-732.

4. Fischer C. Testing scab-resistance stability of new resistant cultivars within the apple breeding program // Fischer C., Schreiber H., Buttner R., Fischer M. / Acta Horticulturae. - 1999. - V. 484. - P. 449-454.

5. Janick J. History of the PRI apple breeding program / Acta Horticulturae. - 2002. V. 595. - P. 55-60.

6. Durel C.E. Genetic dissection of partial resistance to rase 6 of Venturia inaequalis in apple // Durel C.E., Parisi L., Laurens F., Van de Weg W.E., Leirbherd R., Jourjon V.F. / Genome. - 2003. - V. 46(2). - P. 224-234.

7. Afunian M.R. Linkage Vfa4 in Malus h domestica and Malus floribunda with Vf resistanse to the apple scab pathogen Venturia inaequalis / Afunian M.R., Goodwin P.H., Hunter D.M. // Plant Pathology. - 2004. - V. 53. - P. 461-467.

8. Sedov, E.N. Selekcija i novye sorta jabloni / E.N. Sedov. - Orel: VNIISPK, 2011. $624 \mathrm{~s}$.

9. Jakuba, G.V. Struktura patogennogo kompleksa vozbuditelej mikozov nazemnoj chasti rastenija jabloni $\mathrm{v}$ uslovijah izmenenija klimata / G.V. Jakuba // Nauchnye trudy GNU SKZNIISiV - Tom 5. - Krasnodar: GNU SKZNIISiV. - 2014. - S. 151-157.

10. Savel'eva, N.N. Biologicheskie i geneticheskie osobennosti jabloni i selekcija immunnyh k parshe i kolonnovidnyh sortov / N.N. Savel'eva. - Michurinsk-naukograd RF, 2016. $-280 \mathrm{~s}$.

11. Sedov, E.N. Selekcija jabloni na poliploidnom urovne / E.N. Sedov, G.A. Sedysheva, Z.M. Serova, - Orel: VNIISPK, 2008. - 367 s.

12. Sedov, E.N. Sozdanie novyh poliploidnyh sortov jabloni s geneticheskoj ustojchivost'ju k parshe / E.N. Sedov, G.A. Sedysheva, Z.M. Serova, E.V. Ul'janovskaja // Sadovodstvo i vinogradarstvo, 2009. - №1. - S.14-15.

13. Eremin, G.V. Poliploidija / G.V. Eremin, E.V. Ul'janovskaja, V.V. Kovaleva // Sovremennye metodologicheskie aspekty organizacii selekcionnogo processa $\mathrm{v}$ sadovodstve i vinogradarstve. - Krasnodar: SKZNIISiV, 2012. - S. 113-127.

14. Sedov, E. Creation of triploid grades opens a new era in apple-tree selection / E. Sedov, G. Sedysheva, Z. Serova, E. Ulyanovskaya. // Russian Journal of Horticulture. 2014. - T.1. - № 1. - S. 17-24.

15. Ul'janovskaja, E.V. Uskorennoe sozdanie immunnyh $\mathrm{k}$ parshe sortov jabloni $\mathrm{s}$ ispol'zovaniem molekuljarno-geneticheskih metodov issledovanija / E.V. Ul'janovskaja, I.I. Suprun, E.N. Sedov, G.A. Sedysheva, Z.M. Serova. - Krasnodar, 2011. - 55 s.

16. Programma Severo-Kavkazskogo centra po selekcii plodovyh, jagodnyh, cvetochno-dekorativnyh kul'tur i vinograda na period do 2030 goda. - Krasnodar: SKZNIISiV, 2013. - $202 \mathrm{~s}$.

17. Programma i metodika sortoizuchenija plodovyh, jagodnyh i orehoplodnyh kul'tur. - Orel, 1999. - 606 s.

18. Programma i metodika selekcii plodovyh, jagodnyh i orehoplodnyh kul'tur. Orel, 1995. - $503 \mathrm{~s}$.

19. Kompleksnaja programma po selekcii semechkovyh kul'tur $\mathrm{v}$ Rossii na 2001-2020 gg. - Orel, 2001. - 29 s.

20. Metodika provedenija ispytanij na otlichimost', odnorodnost' i stabil'nost'. Jablonja. RTG/0014/2 // http://www.gossort.com/mtd_dus.html [Jelektronnyj resurs]. - 2010. 